ratio for some of the weaker reflexions. These latter values are recorded as equal to, greater than or less than unit in Table 1. The correlation is satisfactory in all cases.

The expected intensity has been calculated based on a unit cell composed of $(1-X) \mathrm{Ca}_{18}\left(\mathrm{Mg}_{0.8} \mathrm{Fe}_{0.2}\right)_{2} \mathrm{Ca}\left(\mathrm{PO}_{4}\right)_{14} \cdot X \mathrm{Ca}_{18^{-}}$ $\left(\mathrm{Mg}_{0.8} \mathrm{Fe}_{0.2}\right)_{2} \mathrm{H}_{2}\left(\mathrm{PO}_{4}\right)_{14}$ for $X=0,0.25,0.50,0.75$ and 1.00 and the result of a selected number of these intensities compared with that corresponding to $X=0$ is shown in Fig. 1. The reflexions chosen are those showing some of the higher sensitivity. Finally, a close examination of the diffraction patterns obtained for the various heat treatments indicates that by $900^{\circ} \mathrm{C}$ the transformation had taken place, because it then had the 006 reflexion clearly visible. Presumably the fact that whitlockite transforms to $\beta \mathrm{Ba}_{3}\left(\mathrm{PO}_{4}\right)_{2}$ at this low temperature will provide information concerning the thermal history of whitlockite after its formation in geological systems.

R. Gopal
C. Calvo

Department of Chemistry, McMaster University, Hamilton, Ontario

Received March 2, 1972.

1 Frondel, C., Amer. Mineral., 26, 145 (1941).

2 Rowles, S. L., Bull. Soc. Chem. France, 1797 (1968).

3 Johnson, M. W., Taylor, B. R., and Berman, D. S., Caries Res., 3, 348 (1969).

4 Albee, A. L., Burnett, D. J., Chodos, A. A., Eugster, O. J., Huncke, J. C., Papanastassiou, D. A., Podosek, F. A., Price Russ II, G., Sanz, H. G., Tera, F., and Wasserburg, E. J., Science, 169, 463 (1970).

${ }^{3}$ Fuchs, L. H., Earth Planet Sci. Lett., 12, 170 (1971).

6 Fuchs, L. H., Science, 137, 425 (1962).

7 Fuchs, L. H., Olsen, E., and Henderson, E. P., Geochemica et Cosmochimica Acta, 31, 1711 (1967).

B Bannister, F. A., Mineral Mag., 28, 29 (1947).

9 Mackay, A. L., thesis, Univ. of London (1952).

10 Keppler, U., News. Jahrb. Mineral. Monatsch., 6, 171 (1965).

11 Gopal, R., and Calvo, C., Canad.J. Chem., 49, 1036 (1971).

12 Gopal, R., thesis, McMaster Univ. (1972).

13 Dickens, B., Bowen, J. S., and Brown, W. E., ACA Winter Meeting Abstracts, 43 (Univ. of South Carolina, 1970)

14 Süsse, P., and Buerger, M. J., Z. Kristallogr., 131, 161 (1970).

\section{Energy and Electric Dipole Moment of the One-Electron Quark Molecules}

THE possible formation of bound quark molecules, recently predicted by Goto, Matsuoka and $\mathrm{Kunii}^{1}$, directs attention to a broad range of molecular and spectroscopic properties which ought to be considered in quark-searching experiments.

Goto et al. ${ }^{1}$ evaluated the equilibrium bond length and energy for the system consisting of a quark, a proton and an electron. Here, we report the energy and electric dipole moment evaluated for both the $+\frac{1}{3} e$ and $+\frac{2}{3} e$ species, over a range of proton-quark distances, using a variational calculation with an extensive set of Gaussians (Fig. 1). The equilibrium parameters are in satisfactory agreement with the exact values evaluated by Goto et al.

We evaluated the electronic dipole moment with respect to the position of the proton. For spectroscopic purposes the dipole moment should be evaluated with respect to the centre of mass. High energy accelerator experiments have set exceedingly high lower bounds for the quark's mass, so the molecular centre of mass should be quite close to the quark. The total electric dipole moment with respect to the centre of mass is therefore almost equal to the electronic dipole moment with respect to the proton. If the quark mass is about ten times higher than the protonic mass, the correction to be applied is less than $10 \%$, in the most interesting range of proton-quark distances.

For $\mathrm{HQ}_{1 / 3}$ the energy curve is rather shallow, but both the dipole moment and its first derivative close to equilibrium are significant.

For $\mathrm{HQ}_{2 / 3}$ the energy curve is much deeper with a considerably higher curvature at the minimum. The location of the

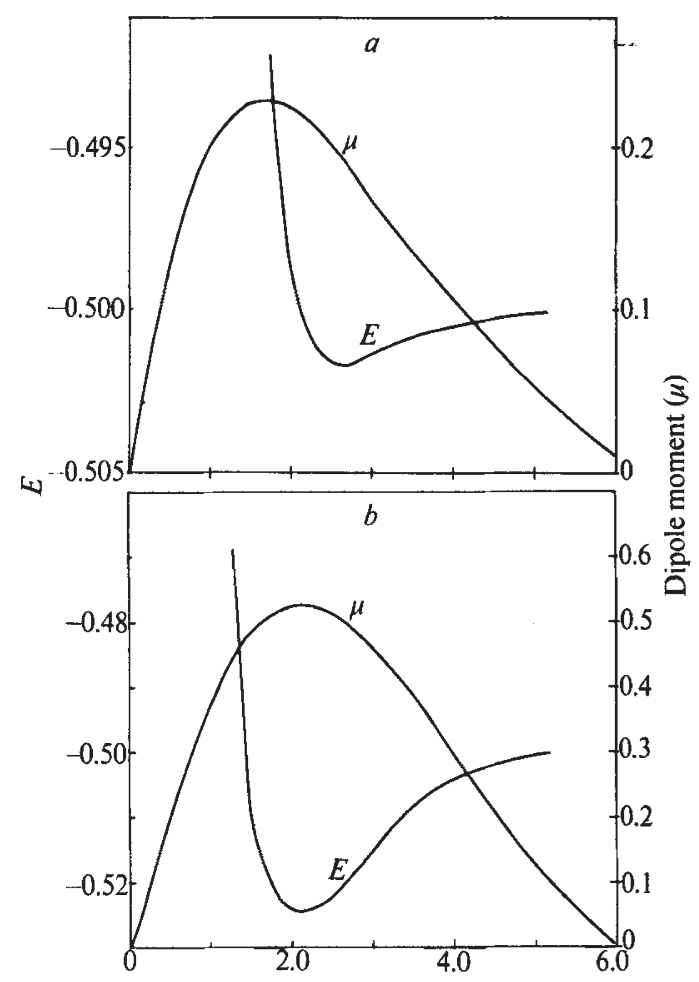

Fig. 1. Total energy and electric dipole moment in atomic units for the quark-proton-electron systems: $a, \mathrm{HQ}_{1 / 3} ; b, \mathrm{HQ}_{2 / 3}$.

extremuln in the dipole moment almost coincides with the equilibrium distance, so $\left.\frac{\mathrm{d} \mu}{\mathrm{d} r}\right|_{\text {eq }}$ is quite small.

The systems considered may thus produce vibrational and rotational spectra as well as a second order Stark effect.

In view of the exceedingly low upper bounds estimated for the terrestrial concentration of quarks it seems impossible to perform laboratory observations of such spectra. The high cosmological abundance of atomic hydrogen may, however, establish favourable conditions for contemplating appropriate experiments.

E. BAR-ZIV

J. KATRIEL

Nuclear Research Center-Negev, PO Box 9001, Beer-Sheva, Israel

Received January 25, 1972.

${ }^{1}$ Goto, E., Matsuoka, O., and Kunii, T. L., Phys. Rev. A., 4, 1380 (1971).

Editorial and Publishing Offices of NATURE MACMILLAN JOURNALS LIMITED 4 LITTLE ESSEX STREET, LONDON WC2R 3LF

Telephone Number: 01-836 6633. Telegrams: Phusis London WC2R 3LF Telex: 262024

711 NATIONAL PRESS BUILDING WASHINGTON DC 20004

Telephone Number: 202-737 2355. Telex: 64280 Subscription Department MACMILLAN JOURNALS LIMITED BRUNEL. ROAD, BASINGSTOKE, HANTS Telephone Number: Basingstoke 29242 American display advertisements NATURE SCIENTIFIC PUBLICATIONS INC. 711 NATIONAL PRESS BUILDING WASHINGTON DC 20004

All other advertisements T. G. SCOTT \& SON, LIMITED

1 CLEMENT'S INN, LONDON WC2A 2ED Telephone 01-242 6264/01-405 4743

Telegrams: Textualist London WC2A 2ED

Registered as a newspaper at the Post Office

Copyright (C) Macmillan Journals Limited, May 81972 